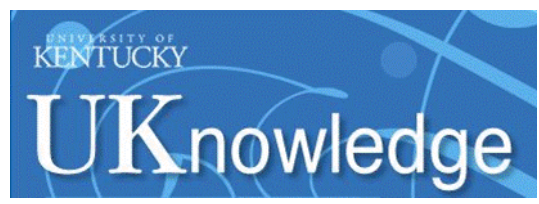

University of Kentucky

UKnowledge

Center for Oral Health Research Faculty

Publications

Oral Health Research

$1-1-2016$

\title{
An Instrument to Measure Dental Students' Communication Skills with Patients in Six Specific Circumstances: An Exploratory Factor Analysis
}

Joanna Alice Aalboe

University of Kentucky, joanna.aalboe@uky.edu

Mitzi M. Schumacher

University of Kentucky, mtzjhns@pop.uky.edu

Follow this and additional works at: https://uknowledge.uky.edu/cohr_facpub

Part of the Dentistry Commons

Right click to open a feedback form in a new tab to let us know how this document benefits you.

\section{Repository Citation}

Aalboe, Joanna Alice and Schumacher, Mitzi M., "An Instrument to Measure Dental Students' Communication Skills with Patients in Six Specific Circumstances: An Exploratory Factor Analysis" (2016). Center for Oral Health Research Faculty Publications. 16.

https://uknowledge.uky.edu/cohr_facpub/16

This Article is brought to you for free and open access by the Oral Health Research at UKnowledge. It has been accepted for inclusion in Center for Oral Health Research Faculty Publications by an authorized administrator of UKnowledge. For more information, please contact UKnowledge@lsv.uky.edu. 


\section{An Instrument to Measure Dental Students' Communication Skills with Patients in Six Specific Circumstances: An Exploratory Factor Analysis}

Notes/Citation Information

Published in Journal of Dental Education, v. 80, no. 1, p. 58-64.

Reprinted by permission of Journal of Dental Education, Volume 80, 1 (January 2016). Copyright 2016 by the American Dental Education Association. http://www.jdentaled.org 


\title{
An Instrument to Measure Dental Students' Communication Skills With Patients in Six Specific Circumstances: An Exploratory Factor Analysis
}

\begin{abstract}
Joanna A. Aalboe, RDH, MPH; Mitzi M. Schumacher, PhD
Abstract: The aim of this study was to explore the internal structure of an instrument assessing dental students' confidence in their ability to communicate with patients in six specific circumstances (anxious, in pain, etc.) using exploratory factor analysis. In a Communication in the Dental Health Care Setting course at a U.S. dental school, second-year dental students in two years (2013 and 2014) responded to the six items on a survey instrument. Of the total 123 students, 122 fully completed the instrument, for a response rate of $99 \%$. Analysis of the results identified a unidimensional scale with regards to patient-specific communication self-efficacy and explained $74 \%$ of the total variance. The scale had good internal consistency reflected by high Cronbach's alpha $(\alpha=0.929,95 \%$ CI $[0.907,0.947])$. These findings suggest the instrument may be a useful tool in assessing the development of patient communication skills in second-year dental students following a course in communication. Further exploration utilizing confirmatory analysis, determining predictive validity, and assessing convergent and discriminant evidence is warranted.
\end{abstract}

Prof. Aalboe is Chief and Assistant Professor, Division of Dental Public Health, Center for Oral Health Research, College of Dentistry, University of Kentucky; Dr. Schumacher is Professor, Department of Behavioral Science, College of Medicine, University of Kentucky. Direct correspondence to Prof. Joanna A. Aalboe, Division of Dental Public Health, Center for Oral Health Research, University of Kentucky College of Dentistry, 1117 S. Limestone, Lexington, KY 40536-0489; 859-323-1167; joanna.aalboe@uky.edu.

Keywords: dental education, attitude of health personnel, patient care management, dentist-patient relations, communication, psychometrics

Submitted for publication 4/3/15; accepted 7/28/15

$\mathrm{E}$ ffective communication skills are vital for all health care professionals including dental practitioners. Studies have found that effective communication skills practiced by health care professionals enhance patient satisfaction, increase patients' likelihood of following provider recommendations, decrease patient anxiety and patient complaints, and reduce malpractice claims. ${ }^{1,2}$ Therefore, prior to graduation and entering private practice, it is key for dental students to acquire adequate levels of communication self-efficacy with patients.

Communication and interpersonal skills are one of the American Dental Education Association (ADEA)'s competency domains for graduating dentists $^{3}$ and are part of the Commission on Dental Accreditation (CODA) standards. ${ }^{4}$ Previous studies have found that dental students' communication skills were significantly improved with training ${ }^{5,6}$ and that dentists, dental students, and patients placed high value on practitioners' interpersonal skills. ${ }^{7,8}$ Most but not all dental schools have distinct courses for teaching interpersonal and communication skills, using methods ranging from lecture and role play- ing to experiential learning with standardized and real patients. ${ }^{9,10}$

It is less clear how the attainment of interpersonal and communication skills is best assessed. The Dental Student Assessment Toolbox, a compendium of approaches to assessing the knowledge, manual and procedural skills, and problem-solving and critical thinking abilities used in U.S. dental schools, noted that four approaches - structured faculty observation, peer assessments, patient surveys, and standardized patient evaluations - were being used to assess students' communication skills. ${ }^{11}$ More specifically, Theaker et al. reported on the development of an instrument for use by faculty and patients to assess student communication skills. ${ }^{12}$ This instrument included a checklist for parts of the interview (e.g., introducing oneself, setting an agenda, and closing an interview) as well as communication skills (e.g., using open-ended questions, summarizing, avoiding jargon, using nonverbal techniques). Understandably, students' self-assessments of their skills were not part of that instrument due to the limits of such selfreports, which may include insufficient expertise to 
make assessments as well as the inability to reflect objectively on one's own abilities. However, one study asked students to report their attitudes and rate their competence regarding communication skills. ${ }^{13}$

Sondell and Soderfeldt conducted a comprehensive review of dentist-patient interaction models that focus on the importance of effective communication. ${ }^{14}$ These researchers categorized 52 examples into empirical models (examining causal factors affecting communication) and normative models (positing standards for evaluating and improving communication). They found that most of those models had been developed for and pertained to medical encounters. However, medical and dental encounters differ significantly from one another in that patient interviews in dentistry must also focus on delivery of treatment, the operatory setting for encounters includes equipment and staff dedicated to treatment delivery, and patients must often communicate despite physical impediments associated with examination of the oral cavity. Overall, these researchers identified four empirical models - one of which was based on self-efficacy - and seven normative models - two of which were based on a biomedical approach and five based on a biopsychosocial approach to provider-patient relationships. Despite their value in understanding factors affecting dentist-patient communication as well as evaluating and improving, these models lack frameworks for teaching communication skills to health care providers.

In contrast, several models have been proposed for teaching communication skills to dental students. Some dental schools have adopted the Macy Foundation's model, which identified seven parts of the medical encounter (preparing, opening, gathering information, eliciting patient perspectives, educating patients, agreeing on treatment plans, and closing the interview) and focused on relationship-building skills and interview-managing skills. ${ }^{15}$ The CalgaryCambridge model in medicine also provides a framework for teaching communication skills, simplifying parts of the patient encounter to initiating the session, gathering information, communicating during the physical exam, and closing the session. ${ }^{16}$ In adapting the medical model to dental education, Haak et al. focused on assessing students' skills associated with each of the parts of the encounter, yielding a ten-item checklist derived from the 38-item Calgary-Cambridge Observation Guide. ${ }^{16}$ Most recently, the Manitoba model, an adaptation of the Macy model, also focused on assessing students' skills, but incorporated aspects of the dental encounter that differentiate it from medical encounters (patients' inability to speak during examinations and procedures and the need to cope with dental anxiety and fear). ${ }^{17,18}$ Similar to the Macy model, the Manitoba model's assessments were based on dimensions of the encounter derived from focus groups comprised of clinicians, stakeholders, and students; those dimensions included being caring and respectful, sharing information, tending to patients' comforts, interacting with team members, and reflecting on experiences with team members. ${ }^{17}$

These models remind us of several points to keep in mind regarding teaching communication skills in health professions education. First, curriculum development based on the models must distinguish between the contexts of medical and dental encounters. Second, the models draw a distinction between substantive parts (e.g., opening, gathering information, and closing) of interviews and specific communication skills (e.g., being attentive, using appropriate language, tending to patients' comfort). Third, these models incorporate assessment of communication skills and particularly students' self-assessment. Developers of the Manitoba model explicitly argue for the importance of students' selfassessments for challenging existing perceptions, highlighting contradictions between knowledge and practice, and motivating change of ineffective behaviors. ${ }^{17,18}$ However, although these models may help guide education in these ways, they do not address learning per se.

While asking students to assess their own skills may not be an optimal way to evaluate their acquisition of interpersonal and communication skills due to the nature of self-report, students' perceptions of their own self-efficacy provide an alternative that may be useful. Self-efficacy has been applied to the learning of skills ${ }^{19-21}$ as well as dentist-patient communication. ${ }^{22-24}$ Self-efficacy, introduced by Bandura as part of his theory of social cognitive learning ${ }^{20}$ is fundamentally the confidence one has in one's own abilities in domains that may contain novel, unpredictable, or stressful features. Importantly, self-assessment should not be thought of as providing a true assessment of students' ability or skill, but rather reflects their confidence in applying knowledge and skills.

Calibration is an indicator of the difference between confidence in a specific situation and actual performance. While Bandura argues that being slightly overconfident is both common and adaptive, feedback can help students accurately calibrate their self-efficacy beliefs..$^{20}$ Self-efficacy is not an indicator 
of attitudes toward a particular subject, but rather the extent to which students believe they can do something well or successfully. The key to understanding an individual's self-efficacy is in the specifics of the situation: identifying what is new, the lack of predictability, or the potential for stress. In teaching, it is important to make sure learners not only understand the fundamentals, but also can apply their knowledge to solve more complex and challenging situations. Research in education, social cognition, and other applied fields has found that self-efficacy motivates learning, influences goal-setting and the choice of tasks, contributes to task perseverance, and is associated with self-regulation and reactions to negative feedback..$^{19,25}$

Promoting communication self-efficacy early in dental students' clinical training provides a foundation for the successful acquisition and implementation of communication skills in a dental career. A systematic review of published articles on dental communication found a lack of psychometrically robust instruments to measure communication selfefficacy in dental education. ${ }^{9}$ Therefore, developing an appropriate tool to assess the result of communication skills training is needed. The aim of this study was to better understand the underlying structure of an instrument developed to assess the self-efficacy of second-year dental students in a one-credit hour communication skills course. The course focused on communication skills required to effectively manage the concerns and treatment of patients in general, anxious patients, patients in pain, challenging patients, and patients who need to change their behaviors. The instrument was aimed at assessing students' self-efficacy in those specific circumstances.

\section{Methods}

Since this study was part of curriculum development in a course on communication in dentistry, the Institutional Review Board of the University of Kentucky College of Dentistry exempted it from further review. The instrument was administered at the first class meeting of the second-year course in communications at the College of Dentistry and again after all work had been completed for the course. The data reported here came from the first administration to two successive years of second-year students (2013 and 2014).

The communication self-efficacy instrument was developed for the Communication in the
Dental Health Care Setting course. The instrument was designed to measure student communication self-efficacy with patients in six circumstances. The instrument measured one construct-confidence in ability to communicate-across six specific situations. These six situations with their item codes were as follows: patients anxious about undergoing dental procedures (AnxPt), patients experiencing dental pain (Pain), patients needing to change their oral health behavior (BhvChg), patients with dental concerns (Concerns), patients needing information about their dental treatment plans (Plans), and challenging patients (depressed, distracted, disabled, etc.) (ChlngPt). The six-item instrument used a ten-point rating scale ranging from $0=$ not at all confident to 9=extremely confident.

Based on Bandura's requirement that the items in a self-efficacy scale include domains relevant to the more global theoretical self-efficacy in which the research is interested ${ }^{26}$ (in this case, self-efficacy regarding second-year dental students' communication skills employed in patient interviewing), the professional standards, course objectives, lecture content, simulated patient cases, and items for the scale were all consistent with one another. Content validity was enhanced through wording synonymous with perceived capability: "confidence in ability to." The domains also represented heterogeneity in the extent of the challenges they represent for learners, resulting in situations that represented routine patients as well as anxious or depressed patients and patients in pain or in need of behavior change counseling. Preston and Coleman recommended a percentage scale for responses, usually taking the simpler form of discrete ten-point intervals or functionally an 11-point scale $(0,10,20$, etc.); they argued that because people avoid extreme responses, the additional response options provide more variance for statistical analyses, which five-point scales are simply unable to provide. ${ }^{27}$ Because we have found that respondents usually prefer 10-point scales and that those scales have similar psychometric properties to a shorter seven-point scale, we chose to use a 10-point response scale.

An exploratory factor analysis (EFA) was conducted to determine the dimensionality of the instrument and was used to provide evidence of content and construct validity. Factor analysis is a statistical procedure used to identify clusters of items that correlate, indicating they measure a common trait. In this way, factor analysis demonstrates that items measuring the same dimension will correlate 
highly as compared to two items measuring similar yet divergent dimensions. The number of factors is an important element of evaluating the internal structure of an instrument and the internal structure of an instrument when considering construct validity. Furr and Bacharach pointed out that "content validity is an important form of evidence in the overall evaluation of construct validity." ${ }^{28}$ According to these researchers, the most widely accepted current definition of validity in the field of measurement is "the degree to which evidence and theory support the interpretations of test scores entailed by the proposed uses." Therefore, validity is concerned with sound interpretations and conclusions drawn from a measure's scores. In this study, we theorized that the instrument was a valid measure of communication self-efficacy and that all items were highly correlated with each other, demonstrated by responses to the test items that exhibited a unidimensional structure consistent with the conceptual definition.

Since our rating scale cannot be assumed to be interval, the data were analyzed as ordinal. Weighted Least Squares (WLSMV) estimation has been found to perform better when data are categorical. ${ }^{29,30}$ Therefore, a polychoric via (WLSMV) estimation EFA in Mplus 7.0 was carried out on the raw data. A parallel analysis on the polychoric correlation matrix using maximum likelihood (ML) estimation was conducted using IBM SPSS, version 22 (IBM Corp., Armonk, NY, USA). Three accepted criteria were considered to determine how many factors to initially extract: the Kaiser criteria, the scree plot, and Horn's parallel analysis.

Internal consistency (reliability) of the instrument is related to the correlations among its items. If an item is weakly correlated with other items on the instrument, we can deduce that the item reduces the internal consistency of the instrument. On the other hand, if the item is relatively strongly correlated with other items on the instrument, we can deduce that this item increases the internal consistency of the instrument. The internal consistency of the items was measured using Cronbach's alpha (coefficient alpha) and item discrimination using item-total correlation.

\section{Results}

A total of 122 out of the total 123 second-year students in the two years completed the instrument, yielding an overall response rate of $99 \%$. One student began the survey but did not answer each item and was not included in the analysis. The composite demographics of the two classes ( $\mathrm{N}=122)$ were $52 \%$ male, $82 \%$ Caucasian (less than 5\% each Asian, African American, Hispanic, and other), and a mean age of 25 years.

The mean self-efficacy scores for each item were as follows: communicating with patients anxious about undergoing dental procedures $(\mathrm{M}=5.89$, $\mathrm{SD}=1.560$ ), patients experiencing dental pain $(\mathrm{M}=5.87, \mathrm{SD}=1.606)$, patients needing to change their oral health behavior $(\mathrm{M}=5.63, \mathrm{SD}=1.560)$, patients with dental concerns $(\mathrm{M}=6.42, \mathrm{SD}=1.620)$, patients needing information about their dental treatment plans $(\mathrm{M}=6.05, \mathrm{SD}=1.705)$, and challenging patients (depressed, distracted, disabled, etc.) $(\mathrm{M}=5.39$, $\mathrm{SD}=1.545)$. All the items on the instrument were highly correlated with each other, forming a single tight cluster of items (Table 1).

The Kaiser-Meyer-Olkin (KMO) measure was used to determine the sample's adequacy. The KMO measure for this study was 0.89 , which is considered an adequate determination of sampling. Bartlett's Test of Sphericity was significant $(p<0.001)$ and supported conducting an EFA. The initial analysis was conducted using WLSMV. The extraction commonalities were examined and revealed that no items had commonalities near 0 , indicating all items contributed to the EFA. Kaiser criterion revealed one

Table 1. Polychoric correlations among items

\begin{tabular}{|c|c|c|c|c|c|c|}
\hline & AnxPt & Pain & BhvChg & Concerns & Plans & ChlngPt \\
\hline AnxPt & 1 & & & & & \\
\hline Pain & 0.849 & 1 & & & & \\
\hline BhvChg & 0.659 & 0.761 & 1 & & & \\
\hline Concerns & 0.652 & 0.724 & 0.610 & 1 & & \\
\hline Plans & 0.645 & 0.703 & 0.574 & 0.801 & 1 & \\
\hline ChlngPt & 0.754 & 0.758 & 0.637 & 0.622 & 0.579 & 1 \\
\hline
\end{tabular}


factor with an Eigenvalue greater than 1. The scree plot showed one main factor prior to the bend in the "elbow" of the plot.

In the parallel analysis, one factor was retained from the number of factors that existed above the crossing point of the two plots (Figure 1). Therefore, a decision was made to extract one factor in the first EFA (Table 2). To verify the decision of one factor, a forced two-factor rotation with WLSMV extraction and an oblique GEOMIN rotation were used because the factors seem to be correlated. The loadings under this rotation showed that AnxPt, Pain, BhvChg, and ChlngPt loaded highly on factor 1 , with concerns loading on factor 2 and plans cross-loading (Table 3 ). The factor structure was examined and revealed high cross-loading on both factors, indicating that a one factor solution was tenable (Table 4). Based on these findings, no additional attempts to extract factors were attempted.

Results from this EFA suggested the structure of the instrument was one-dimensional with regards to patient communication self-efficacy under specific circumstances. The factor was named by applying a descriptive label. Factor 1, Patient and CircumstanceSpecific Communication Confidence, included six items that related to the students' perceived ability

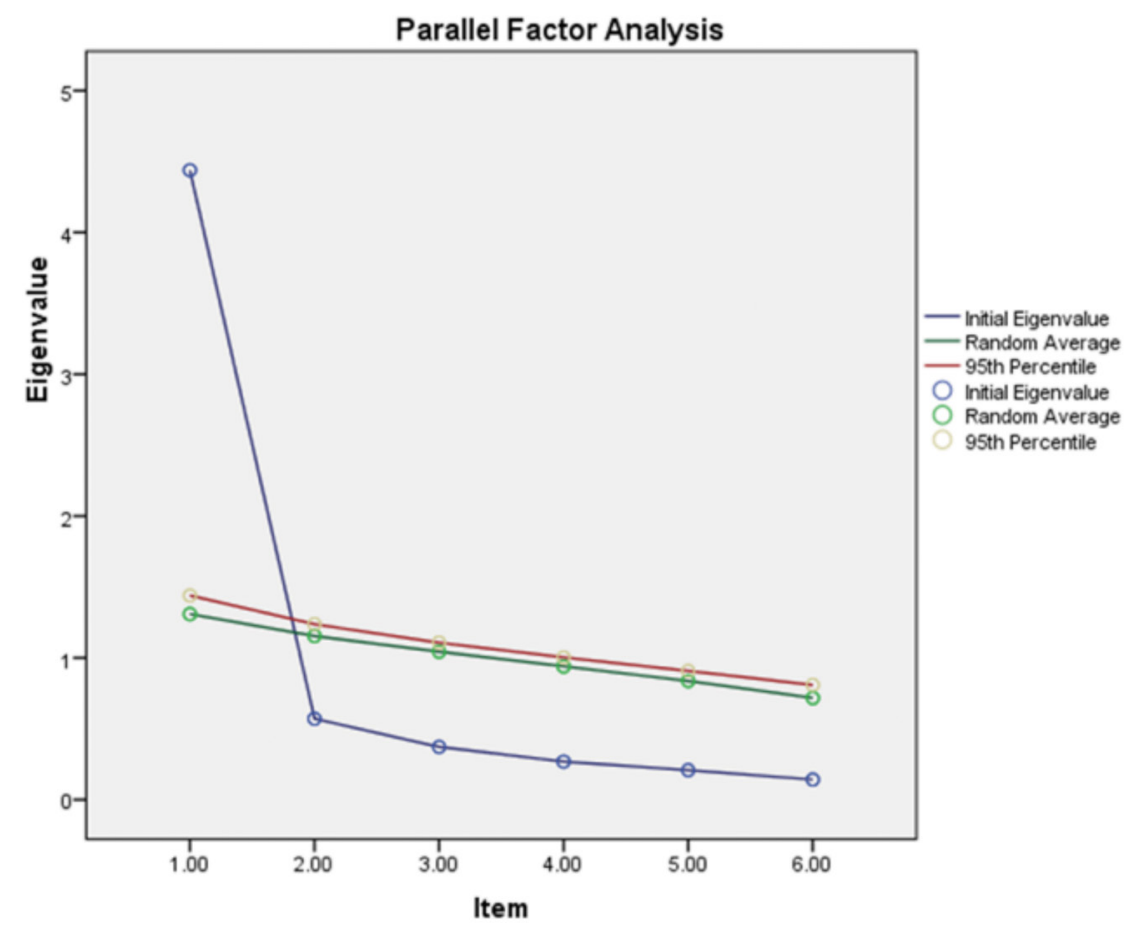

Figure 1. Scree plot of actual Eigenvalues and random Eigenvalues from parallel factor analysis

\section{Table 2. Pattern matrix with loadings for each of six items on one factor}

Item

Your confidence in your ability to communicate with an anxious patient (AnxPt)

*Weighted Least Squares estimation in MPlus categorical specified. All loadings were statistically significant. 
to communicate with dental patients. This factor explained about $74.2 \%$ of the total variance. There were no factor loadings less than 0.760 , with one item greater than 0.90 .

The instrument was found to have a high level of reliability (Cronbach's alpha) $(\alpha=0.929,95 \%$ CI $[0.907,0.947])$, demonstrating that the construct adequately measured the communication items under assessment. The corrected item-total correlation was positive, consistent, and highly correlated, indicating that the item was consistent with the test as a whole (Table 5). The Cronbach's alpha in the item deleted column tells us that the items are reliable and that if we removed any items, the overall internal consistency would not be improved, further supporting the internal consistency of the instrument.

\section{Discussion}

This study involved a preliminary exploration of the internal structure of a new instrument, including its reliability and validity, to assess second-year dental students' confidence to communicate with patients in six specific circumstances. The results provided a number of useful outcomes in the context of the study sample focusing on confidence in communication skills garnered from the course. First, the instrument had acceptable psychometric properties, with no indication of superfluous items. Second, one distinct factor was identified, which was labelled "Patient and Circumstance Specific Communication Confidence." The results sustained the postulate of a unidimensional instrument. The factor was consistent with the intent of the instrument, which was designed to measure one latent variable under six patient and circumstance-specific categories. Specifically, all the items on the instrument were highly correlated with each other, forming a single tight cluster of items. This translates to the instrument being a valid measure of communication self-efficacy.

Dental educators can use this instrument to identify second-year dental students who do not feel confident communicating with patients in specific situations after taking the course. Dental educators then would take appropriate actions to increase the students' efficacy perceptions with patient-specific communication item identified by the instrument. Further analysis of the instrument utilizing confirmatory analysis applied to a new and larger sample, estimate of predictive validity, and convergent and discriminant evidence is recommended.

\section{Table 3. GEOMIN rotated loadings}

\begin{tabular}{lcc} 
Item & Factor 1 & Factor 2 \\
\hline AnxPt & 0.933 & -0.048 \\
Pain & 0.921 & 0.037 \\
BhvChg & 0.727 & 0.065 \\
Concerns & -0.002 & 0.990 \\
Plans & 0.258 & 0.614 \\
ChlngPt & 0.823 & -0.006
\end{tabular}

AnxPt=anxious patient; Pain=patient in pain; BhvChng=patient needing behavior change; Concerns=patient with dental concerns; Plans=patient needing information about treatment plan; ChlngPt=challenging patient (depressed, distracted, disabled, etc.)

Table 4. Factor structure coefficients

\begin{tabular}{lcc} 
Item & Factor 1 & Factor 2 \\
\hline AnxPt & 0.897 & 0.662 \\
Pain & 0.949 & 0.738 \\
BhvChg & 0.776 & 0.618 \\
Concerns & 0.752 & 0.988 \\
Plans & 0.725 & 0.810 \\
ChlngPt & 0.819 & 0.621
\end{tabular}

AnxPt=anxious patient; Pain=patient in pain; BhvChng=patient needing behavior change; Concerns=patient with dental concerns; Plans=patient needing information about treatment plan; ChlngPt=challenging patient (depressed, distracted, disabled, etc.)

Table 5. Item-total statistics

$\begin{array}{cc}\text { Item } & \begin{array}{c}\text { Corrected } \\ \text { Item-Total } \\ \text { Correlation }\end{array} \\ \text { Alpha If Item } \\ \text { Deleted }\end{array}$

\begin{tabular}{lll}
\hline AnxPt & 0.819 & 0.913 \\
Pain & 0.892 & 0.903 \\
BhvChg & 0.740 & 0.923 \\
Concerns & 0.783 & 0.917 \\
Plans & 0.760 & 0.921 \\
ChlngPt & 0.769 & 0.919
\end{tabular}

AnxPt=anxious patient; Pain=patient in pain; BhvChng=patient needing behavior change; Concerns=patient with dental concerns; Plans=patient information about treatment plan; ChlngPt=challenging patient (depressed, distracted, disabled, etc.)

\section{Conclusion}

The development of a valid tool to assess dental students' communication self-efficacy under patient-specific circumstances is pertinent. This study found that the instrument tested demonstrated the potential for being an effective tool in providing 
valid data to determine successful communication training in dental school. Scores on the communication self-efficacy scale were validly interpreted as a measure of the students' confidence to communicate with situation-specific patients. The results suggest that this instrument can help to inform the development of appropriate patient communication skills of second-year dental students following a course in communication.

\section{Acknowledgments}

We thank Michael D. Toland, PhD, from the University of Kentucky for being an integral part of the process by providing guidance in psychometric methods.

\section{Disclosure}

The authors declared no actual or potential conflicts of interest and made no financial disclosures.

\section{REFERENCES}

1. Huntington B, Kuhn N. Communication gaffes: a root cause of malpractice claims. Proceedings (Baylor Univ Med Center) 2003;16:157-61.

2. Van der Molen H, Klaver A, Duyx M. Effectiveness of a communication skills training program for the management of dental anxiety. Br Dent J 2004;196(2):101-7.

3. American Dental Education Association. ADEA competencies for the new general dentist. J Dent Educ 2015;79(7):813-6.

4. Commission on Dental Accreditation. Accreditation standards for dental education programs. 2013. At: www.ada. org/en/coda/current-accreditation-standards/. Accessed 3 Apr. 2015.

5. Hottel TL, Hardigan PC. Improvement in the interpersonal communication skills of dental students. J Dent Educ 2005;69(2):281-4.

6. Wagner J. A patient-instructor program to promote dental students' communication skills with diverse patients. J Dent Educ 2007;71(12):1554-60.

7. Kulich KR, Ryden O, Bengtsson H. A descriptive study of how dentists view their own profession and the doctorpatient relationship. Acta Odontol Scand 1998;56(4): 206-9.

8. Woelber JP, Deimling D, Langenback D, Ratka-Kruger P. The importance of teaching communication in dental education: a survey amongst dentists, students, and patients. Eur J Dent Educ 2011;16:200-4.

9. Carey J, Madill A, Manogue M. Communication skills in dental education: a systemic review. Br Dent J 2010;14(2):69-78.

10. Yoshida T, Milgrom P, Coldwell S. How do U.S. and Canadian dental schools teach interpersonal communication skills? J Dent Educ 2002;66(11):1281-8.

11. Kramer GA, Albino JEN, Andrieu SC, et al. Dental student assessment toolbox. J Dent Educ 2009;73(1):12-35.
12. Theaker ED, Kay EJ, Gill S. Development and preliminary evaluation of an instrument designed to assess dental students' communication skills. Br Dent J 2000;188:40-4.

13. McKenzie CT. Dental student attitudes towards communication skills instruction and clinical application. J Dent Educ 2014;78(10):1388-96.

14. Sondell K, Soderfeldt B. Dentist-patient communication: a review of relevant models. Acta Odontol Scand 1997;55:116-26.

15. Kalet A, Pugnaire MP, Cole-Kelly K, et al. Teaching communication in clinical clerkships: models from the Macy initiative in health communications. Acad Med 2004;79(6):511-20.

16. Haak R, Rosenbohm J, Koerfer A, et al. The effect of undergraduate education in communication skills: a randomized controlled clinical trial. Eur J Dent Educ 2008;12:213-8.

17. Wener ME, Schonwetter DJ, Mazurate N. Developing new dental communication skills assessment tools by including patients and other stakeholers. J Dent Educ 2011;75(12):1527-41.

18. Winning TA, Kinnell A, Wener ME, et al. Validity of scores from communication skills instruments for patients and their dental student-clinicians. Eur J Dent Educ 2012;17:93-100.

19. Artino AR. Academic self-efficacy: from educational theory to instructional practice. Perspect Med Educ 2012;1:76-85.

20. Bandura A. Self-efficacy: toward a unifying theory of behavioral change. Psychol Rev 1977;84(2):191-215.

21. Mann K, McFetridge-Durdle J, Breau L, et al. Development of a scale to measure health professions students self-efficacy beliefs in interprofessional learning. J Interprof Care 2012;26:92-9.

22. Kakudate N, Morita M, Fukuhara S, et al. Application of self-efficacy theory in dental clinical practice. Oral Dis 2010;16(8):747-52.

23. Syrjala AM, Knuuttila ML, Syrjala LK. Self-efficacy perceptions in oral health behavior. Acta Odontol Scand 2001;59(1):1-6.

24. Wolfe G, Stewart J, Hartz G. Relationship of dental coping beliefs and oral hygiene. Community Dent Oral Epidemiol 1991;19:112-5.

25. Pajares F. Advances in motivation and achievement. In: Maehr M, Pintrich PR, eds. Current directions in selfefficacy research. Vol. 10. Greenwich, CT: JAI Press, 1997:1-49.

26. Bandura A. Self-efficacy beliefs of adolescents. In: Pajares F, Urdan T, eds. Guide for constructing self-efficacy scales. Vol. 5. Greenwich, CT: Information Age Publishing, 2006:307-37.

27. Preston CC, Colman AM. Optimal number of response categories in rating scales: reliability, validity, descriminating power, and respondent preferences. Acta Psychol 2000;104:1-15.

28. Furr MR, Bacharach VR. Psychometrics: an introduction. 2nd ed. Los Angeles: Sage, 2014.

29. Muthen B. Contribution to factor analysis of dichotomous variables. Psychometrika 1978;43(4):551-60.

30. Muthen B. A general structural equation model with dichotomous, ordered categorical, and continuous latent variable indicators. Psychometrika 1984;49:115-32. 